\title{
STUDY ON CONSTITUTIVE EQUATION OF ALLOY IN718 IN HAMMER FORGING PROCESS
}

\author{
J.P. Hu*, J.Y. Zhuang"*, Z.Y. Zhong** \\ P. Janschek ${ }^{* * *}$, J. Kramer ${ }^{* * *}$ \\ "Rolling Department, Chongqing Iron and Steel Designing \\ Research Institute, YuZhongQu, Chongqing (400013), China \\ "High Temperature Materials Research Institute, \\ Central Iron and Steel Research Institute, Beijing (100081), China \\ "**Thyssen Umformtechnik GmbH, 42859 Remscheid, Germany
}

\begin{abstract}
Effect of hot-deformation parameters of alloy In718 on the flow stress in the hammer forming process was analyzed in detail via axial compression testing of cylindrical specimens. All tests were conducted at a constant strain rate of $10 \mathrm{~s}^{-1}$. The total strain of 0.7 was obtained by three consecutive passes or five. The deformation temperature ranged from $960^{\circ} \mathrm{C}$ to $1040^{\circ} \mathrm{C}$. The interval time was $5 \mathrm{~s}$ between any two consecutive passes. The complex multi-pass true stressstrain curves in the hammer forging process were reasonably simplified according to the unloading point of every pass, and the continuous stress-strain curves were obtained. The continuous simplified stress-strain curves approximately reflected the changing trends of multi-pass stress-strain curves. These continuous and simplified curves were described quantitatively in mathematics, and then constitutive equation reflecting the relationship between the flow stress and hot-deformation parameters was set up successfully.
\end{abstract}

Superalloys 718,625,706 and Various Derivatives

Edited by E.A. Loria

TMS (The Minerals, Metals \& Materials Society). 2001 


\section{Introduction}

In modern aeroengines, alloy $\operatorname{In} 718$ is often utilized to manufacture turbine disc. Generally speaking, turbine discs are manufactured through thermomechanical processing (TMP), which is the main technology of controlling the quality of turbine disc. The microstructure and mechanical properties of alloy In718 parts are highly sensitive to TMP. In order to obtain the most-favorable microstructure and the best mechanical properties of turbine disc, computer simulation of the hot-deformation behavior and microstructure of alloy $\operatorname{In} 718$ has been becoming one hot in recent years [1-5] in the world. So far, many achievements have been made for the studies on the deformation behavior of alloy In718 in the isothermal forging process [1-8], which was called as the first step of manufacturing the turbine disc. However, there were few reports on the hammer forging process in the world [1-8], which was called as the second step of manufacturing the turbine disc. This article focuses on the studies on deformation behavior of alloy In718 in the hammer forging process. Constitutive equation reflecting the complex multi-pass true stress-strain curves was reasonably established.

\section{Experiment Material and Method}

Cylindrical compression specimens of In718 with a diameter of $20 \mathrm{~mm}$ and a height of $30 \mathrm{~mm}$, as shown in Figure1 (a), were machined from one slice with a diameter of $300 \mathrm{~mm}$ and a thickness of $40 \mathrm{~mm}$. There is a little difference of the macrostructure at center, midradius, and outside diameter of the slice. To minimize the scatter of the initial microstructure, the location of compression specimens are shown in Figurel (b). Cylindrical specimens were compressed at a constant strain rate of $10 \mathrm{~s}^{-1}$ on the High Speed Testing Machine at Aachen University of Germany. Before compression tests, grooves with a diameter of $18 \mathrm{~mm}$ and a height of $0.2 \mathrm{~mm}$ were machined at the two ends of specimens to retain lubricant during the hot-deformation process. A fine glass lubricant was spread in the grooves to minimize barreling effect [7].

Table I Chemical Composition of Alloy In718 (wt. \%)

\begin{tabular}{l|l|l|l|l|l|l|l}
\hline Element & $\mathrm{Ni}$ & $\mathrm{Fe}$ & $\mathrm{Cr}$ & $\mathrm{Nb}$ & $\mathrm{Mo}$ & $\mathrm{Ti}$ & $\mathrm{Al}$ \\
\hline In718 & $\mathrm{Bal}$. & 18.99 & 18.32 & 5.18 & 3.05 & 0.98 & 0.55 \\
\hline Element & $\mathrm{Co}$ & $\mathrm{Cu}$ & $\mathrm{Si}$ & $\mathrm{C}$ & $\mathrm{P}$ & $\mathrm{B}$ & $\mathrm{S}$ \\
\hline In718 & 0.35 & 0.06 & 0.21 & 0.044 & 0.009 & 0.0043 & 0.002 \\
\hline
\end{tabular}

The hammer forging process, in which 20-30 deformation passes or so should be adopted to complete the whole deformation process, differs from the isothermal forging process. Further, there existed the interval times between any two deformation passes of the hammer forging process Therefore, experimental schedule is very important to simulate the practice hammer forging process.

Deformation temperatures range from $960^{\circ} \mathrm{C}, 980^{\circ} \mathrm{C}, 1000^{\circ} \mathrm{C}, 1020^{\circ} \mathrm{C}$, to $1040^{\circ} \mathrm{C}$. Specimens were heated up to deformation temperatures and hold 30 minutes before deformation. Then the compressed specimens were hold 0 minute, 10 minutes, and 30 minutes after deformation. The holding time of 0 minute means the compressed specimens were quenched in water immediately after deformation to observe the deformed microstructure. The interval times are $5 \mathrm{~s}$ between any consecutive two passes. 


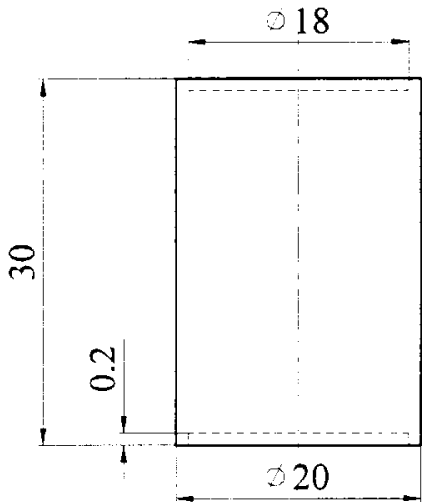

(a)

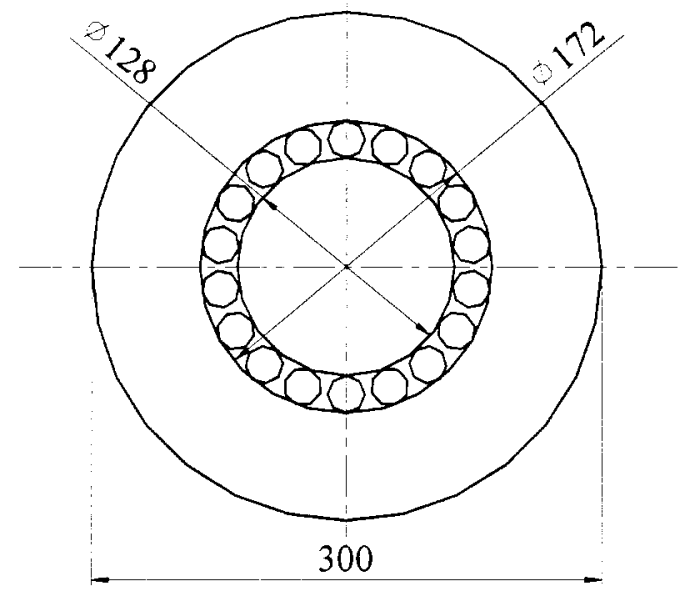

(b)

Figure 1: Size (a) and location (b) of compression specimens used in present work.

Though it needs $20-30$ passes or so to complete the whole forging process, $70 \%$ of the total strain should centralize the front deformation passes using the higher temperature of specimens. The high temperature of the specimen enables large strain per pass without the onset of fracture. In this present work, 3-pass and 5-pass deformation schedules, in which the total strain reaches 0.7 through 3 deformation passes or 5 deformation passes, have been adopted. Engineering strain is valid in the present work since engineering strain is often used during the practice forging process.

The distribution of engineering strain for 3-pass deformation schedule is $0.4,0.2$, and 0.1 for the first, the second, and the third pass respectively. The total strain attains 0.7 $(0.4+0.2+0.1)$. The distribution of engineering strain for 5-pass deformation schedule is 0.25 , $0.15,0.15,0.10$, and 0.05 for the first, the second, the third, the fourth, and the fifth pass respectively. The total strain also attains $0.7(0.25+0.15+0.15+0.10+0.05)$.

The whole compression tests were controlled by computer and the recorded loaddisplacement curves have been converted into the true stress-strain curves, as shown in Figure 2 . Compressed specimens were cut into half along the longitudinal axis to observe the microstructure. Optical microscope was employed for documenting the alloy In718 microstructure.

\section{Results and Discussion}

Simplification of True Stress-Strain Curves

Figure 2 shows the true stress-strain curves reflecting the thermomechanical history of compressed specimens for 3-pass and 5-pass deformation schedules. There are unloading, holding, and reloading processes between any consecutive two deformation passes from these stress-strain curves. Hence, when simulating complex multi-pass hammer forging process, the semi-empirical mathematical description of the stress-strain curves loses its validity [6]. It seems that every single pass should be quantified respectively for the whole stress-strain curves. Fox example, if using increment of flow stress values $(\Delta \sigma)$ corresponding to the beginning point and ending point per single pass, but it is complex to express it in mathematics and 
difficult to explain it in physics. So, a new simplification approach was attempted. In present experimental schedule, the interval times are 5 seconds and do not change between any two consecutive passes. So, the effect of the interval times on the flow stress can be considered as one constant state variable for 3-pass and 5-pass deformation schedules respectively. In this case, the stress-strain curves can be described in course of another way. For example, if all the flow stress values corresponding to the unloading point per single pass were recorded, as shown in Figure3, scatter distribution of flow stress with strain can be got. Then all scatter data were connected as one consecutive curve. This curve was called as the simplified stress-strain curve of the multi-pass true stress-strain curve.
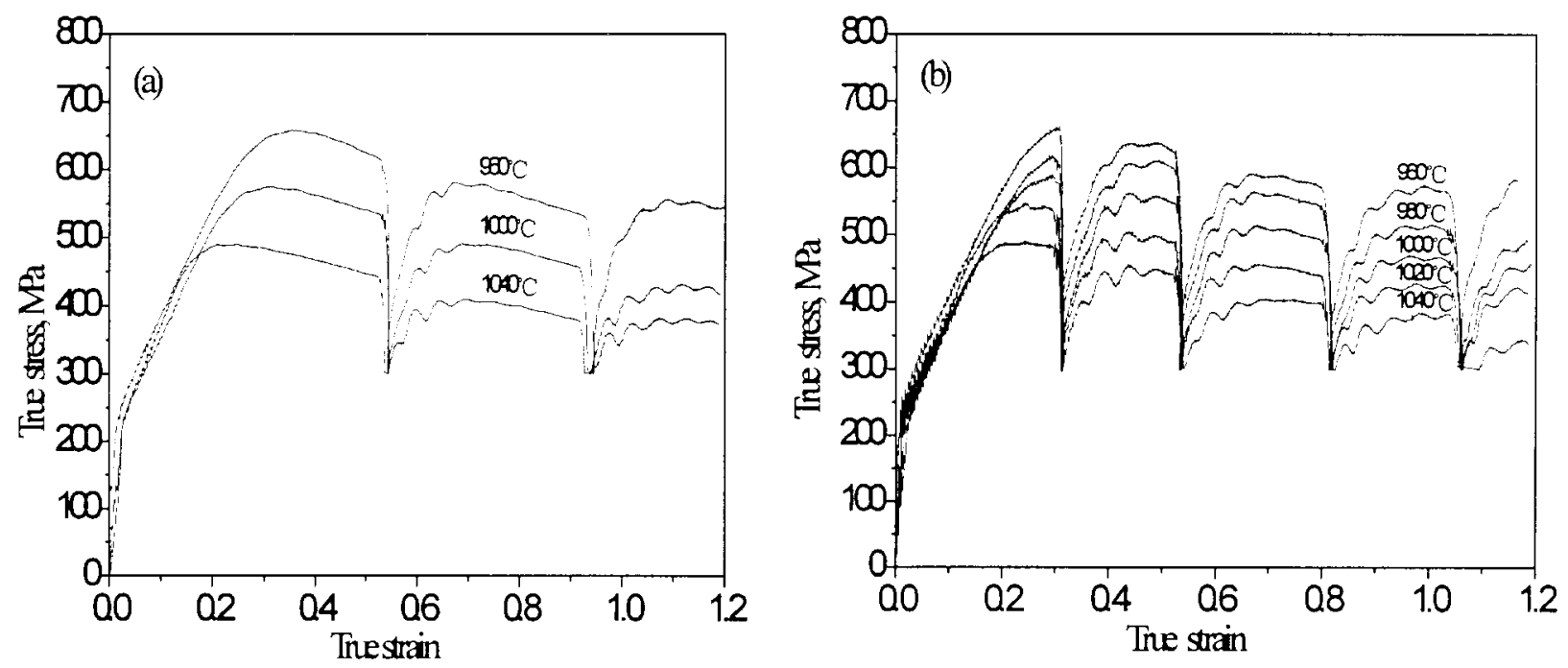

Figure 2: True stress-strain curves of the compressed specimens

(a) 3-pass deformation schedule (b) 5-pass deformation schedule

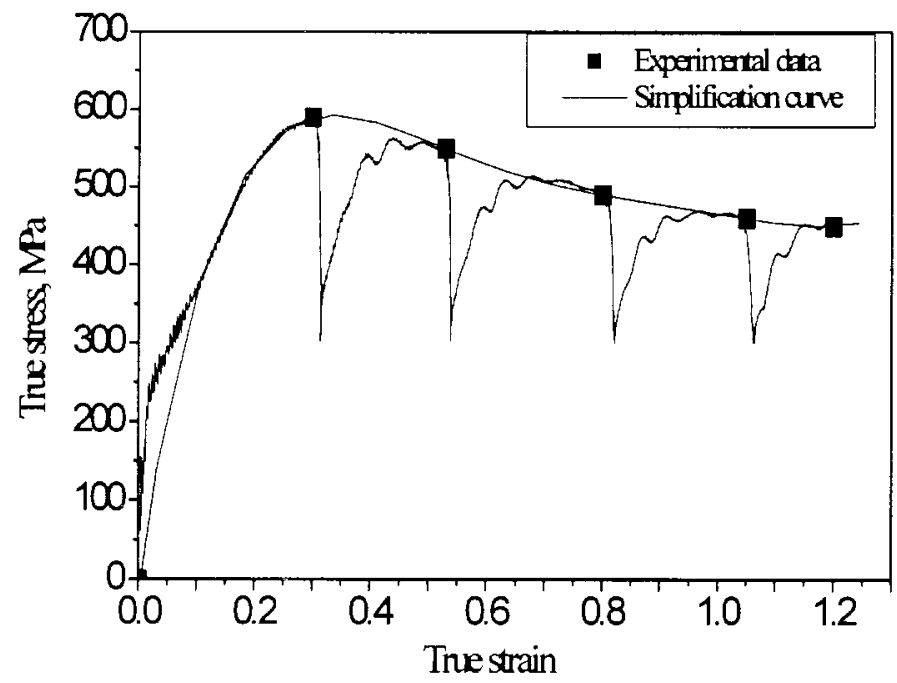

Figure 3: Simplification of the true stress-strain curve for 5-pass deformation schedule, the deformation temperature is $1000^{\circ} \mathrm{C}$

In Figure3, this simplified curve integrates the influence of work hardening, dynamic recrystallized softening, deformation passes and static recrystallized softening within the interval times and excellently describes the true thermomechanical history. So, it is reasonable 
A serial of flow stress values can be obtained from Figure2 as the simplification way shown in Figure3. Scatter distributions of flow stress with strain for 3-pass and 5-pass deformation schedules are shown in Figure4. The true strain was converted into engineering strain, which was explained above.

(1) In Figure4, it is found that flow stress increases at the beginning and then decreases with increasing of engineering strain at the same deformation temperature. Work hardening is larger than recrystallized softening at the beginning in Figure4. This relationship can be described as the following formula,

$$
\sigma=\mathrm{A}_{1} \times \varepsilon^{\mathrm{n}}
$$

Where $A_{1}$ is coefficient, $\varepsilon$ is the engineering strain, and $n$ is work-hardening exponent.

However, with increasing of engineering strain, due to deformation heating, which favors dynamic recovery and recrystallization, flow stress decreases remarkably. The following formula reflects the changing trends,

$$
\sigma=\mathrm{A}_{2} \times \exp (\mathrm{f}(\varepsilon))
$$

Where $A_{2}$ is coefficient, $\varepsilon$ is the engineering strain.

To express the comprehensive results of $\varepsilon$ on the flow stress, the following integrated formula was set up,

$$
\sigma=A_{0} \times \varepsilon^{n} \times \exp (f(\varepsilon))
$$

Where $A_{0}$ is coefficient, $\varepsilon$ is the strain engineering strain and $n$ is the work-hardening exponent sensitive to strain rate.
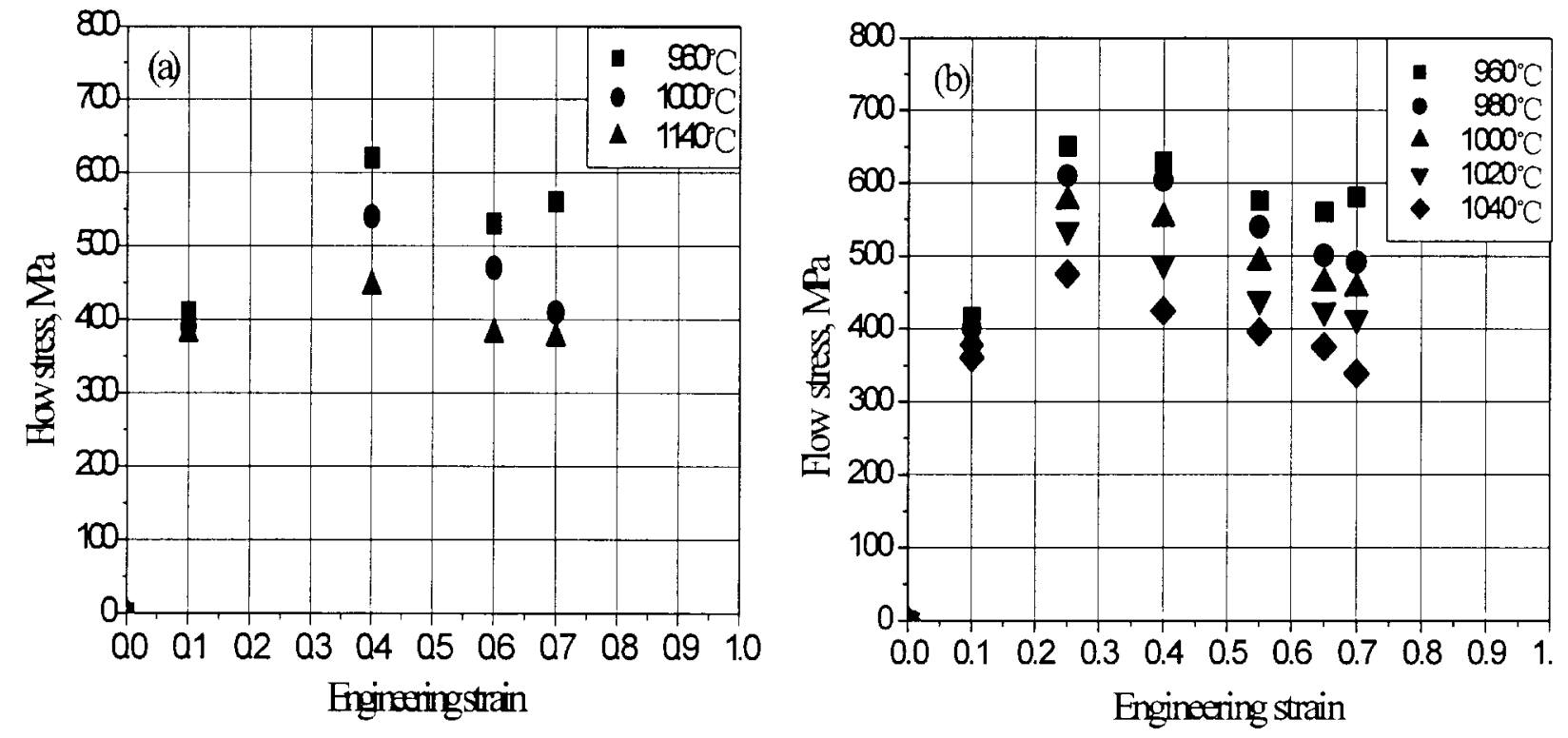

Figure 4: Scatter figures of the flow stress with the engineering strain (a) 3-pass deformation schedule (b) 5-pass deformation schedule 

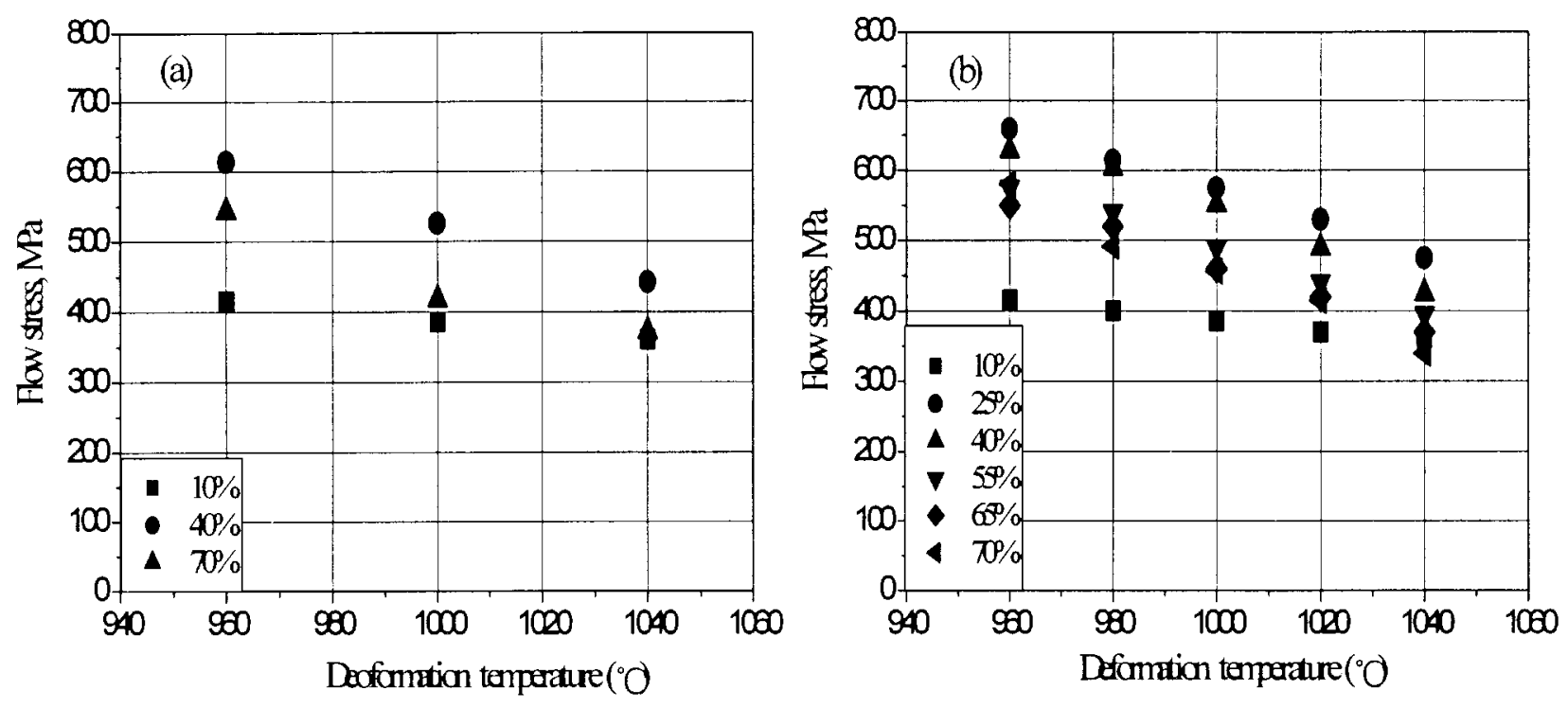

Figure 5: Scatter figures of flow stress with the deformation temperature

(a) 3-pass deformation schedule (b) 5-pass deformation schedule

(2) Figure5 demonstrates the flow stress decreases with increasing of deformation temperature when the strain keeps constant. When deformation temperature is more than $960^{\circ} \mathrm{C}$, $\gamma^{\prime}$ and $\delta$ phases have completely dissolved. So, dynamic recovery and recrystallization occur rapidly. Recrystallized softening enhances and flow stress decreases exponentially. The relationship between the flow stress and the deformation temperatures can be written as follows,

$$
\sigma=B_{0}+B_{1} \times \exp \left[\left(B_{2}-T_{0}\right) / B_{3}\right]
$$

Where $\mathrm{T}_{0}=(\mathrm{T}-940) / 20.0, \mathrm{~T}$ is deformation temperature $\left({ }^{\circ} \mathrm{C}\right) . \mathrm{B}_{0}, \mathrm{~B}_{1}, \mathrm{~B}_{2}$, and $\mathrm{B}_{3}$ are correlative coefficients.

\section{Constitutive Equation and Simulation Results}

The relationships between the flow stress and hot-deformation parameters have been listed as Eqs. (1c) and (2). Flow stress is the function of strain and deformation temperature at the constant strain rate of $10 \mathrm{~s}^{-1}$. From Figures 4 and 5 , it is found that the strains determine the shapes of the stress-strain curves and deformation temperatures have the effect on the scale of stress-strain curves. So, the synthesized constitutive equation can be presented as follows,

$$
\sigma=\mathrm{A} \times \varepsilon^{\mathrm{n}} \times \exp \times(\mathrm{f}(\varepsilon)) \times\left(\mathrm{C}_{0}+\mathrm{C}_{1} \times \exp \left(\left(\mathrm{C}_{2}-\mathrm{T}_{0}\right) / \mathrm{C}_{3}\right)\right)
$$

where $A, C_{0}, C_{1}, C_{2}$, and $C_{3}$ are correlative coefficients, $\varepsilon$ is engineering strain, $T_{0}=(T-940) / 20.0$, $\mathrm{T}$ is deformation temperature $\left({ }^{\circ} \mathrm{C}\right)$. Constitutive equations for the 3-pass and 5 -pass deformation schedules are same with different correlative coefficients.

Though the form of constitutive equation, as shown equation 3 , is similar with others [4$6,8]$, this equation from the simplified schedule discussed above contains the comprehensive factors such as strain, deformation temperature, multi-pass, and interval times. So, this equation 
expresses the constitutive relationship in the hammer forging process of alloy IN718.

Simulation curves, which were plotted according to constitutive equation, are consistent with recorded experimental data in Figure6 (for 5-pass deformation schedule). The simplified schedule of stress-strain curves, which can excellently describe the true thermomechanical history, is feasible. In order to validate its rationality under various initial microstructures and other strain rates, it is necessary to do some complementary tests to perfect the whole constitutive equation so that it can be applied for other kinds of conditions.

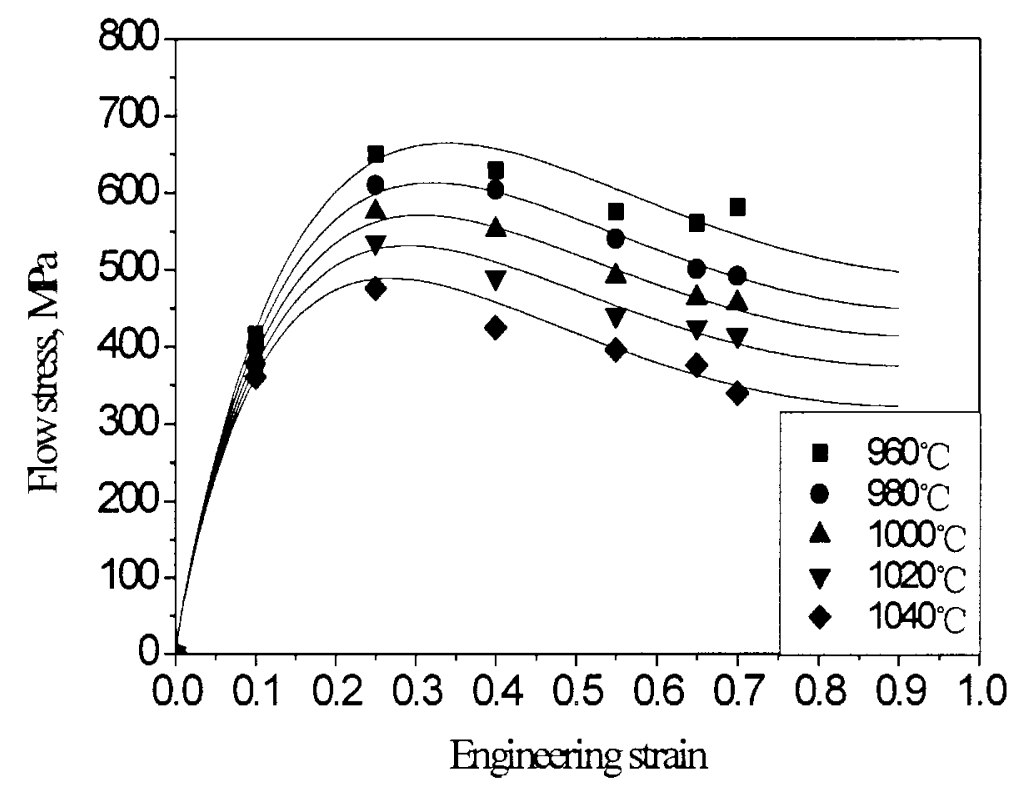

Figure6: Comparison of the simulated curves and experimental data

(5-pass deformation schedule)

\section{Conclusions}

1. A new simplified approach of the multi-pass stress-strain curves synthesized the effect of hot-deformation parameters on flow behavior was attempted in present work and the simulation curves calculated by equation (3) are consistent with the experimental data. It proves that the simplification is reasonable.

2. Flow stress is a function of all hot-deformation parameters. When the temperature increases, flow stress decreases, which shows the existence of dynamic softening in Alloy In718. When the strain increases, the flow stress increases at first and then decreases due to the comprehensive effects of work hardening and dynamic softening.

3. According to the simplification approach, constitutive equation of alloy $\operatorname{In} 718$ at the strain rate of $10 \mathrm{~s}^{-1}$ in the counter-blow hammer forging process has been set up as:

$$
\sigma=A \times \varepsilon^{\mathrm{n}} \times \exp (\mathrm{f}(\varepsilon)) \times\left(\mathrm{B}_{0}+\mathrm{B}_{1} \times \exp \left(\left(\mathrm{B}_{2}-\mathrm{T}_{0}\right) / \mathrm{B}_{3}\right)\right)
$$

\section{References}

1. "Effect of Starting Grain Size on As-Deformed Microstructure in High Temperature Deformation of Alloy718," Superalloys718, 625,706 and Various Derivatives, ed. E.A.Loria (Warrendale, PA: The Metallurgical Society, 1994), 303-313 
2. "Thermomechanical Processing and Continuous Cooling Transformation Behavior of IN718," Superalloys 1992, ed. E.A. Loria (Warrendale, PA: The Metallurgical Society, 1992), $527-536$

3. "Effect of Hot Deformation Parameters on the Grain Size of Wrought In718," Superallolys718, 625,706 and Various Derivatives, ed. E.A. Loria (Warrendale, PA: The Metallurgical Society, 1997), 183-192

4. J.M. Zhang et al., "Mathematical Modeling of the Hot-Deformation Behavior of Superalloy In718," Metallurgical and Materials Transactions A, 30(A) (1999), 2701-2713

5. "High Temperature Deformation Behavior of Cast Alloy718," Superalloys718, 625,706 and Various Derivatives, ed. E.A. Loria (Warrendale, PA: The Metallurgical Society, 1997), 193-205

6. "Two Step Forging of Alloy718," Superalloys718, 625,706 and Various Derivatives, ed. E.A. Loria (Warrendale, PA: 1997), 173-182

7. J.M. Zhang, et al., "Constitutive Relationship of Superalloy In718," ACTA Metallurgical Sinica, 9 (6) (1996), 359-367

8. "Comparison of Single and Multiple Pass Compression Tests Used to Simulate Microstructure Evolution during Hot Working of Alloy718 and 304L," Superalloys718, 625,706 and Various Derivatives, ed. E.A.Loria (Warrendale, PA: The Metallurgical Society, 1994), 331-343 